\title{
ARTIGO TÉCNICO \\ IDENTIFICAÇÃO DE REQUISITOS DE CLIENTES PARA O PROJETO DE UM DOSADOR DE PRECISÃO PARA SEMENTES MIÚDAS ${ }^{1}$
}

\section{ÂNGELO V. DOS REIS ${ }^{2}$, FERNANDO A. FORCELLINI ${ }^{3}$}

\begin{abstract}
RESUMO: A elevação do custo das sementes miúdas torna necessário o desenvolvimento de semeadoras que tenham controle efetivo sobre a população de plantas, o que pode ser conseguido com a utilização de semeadoras de precisão, as quais, no entanto, não são adequadas aos pequenos espaçamentos entre linhas dessas culturas. Por se tratar de um produto novo, há que se prestar especial atenção ao processo de projeto que será utilizado, de forma a incorporar todos os atributos indispensáveis ao cumprimento da tarefa a que se destina, incluindo-se os de ordem funcional, os de qualidade, os comerciais e os de fabricabilidade. Sendo assim, o presente trabalho tem o objetivo de apresentar os requisitos dos clientes para o projeto de um dosador de precisão para sementes miúdas, identificados com a aplicação de um questionário de campo a agricultores, pesquisadores, vendedores, projetistas, e com informações técnicas obtidas na bibliografia. Foram sintetizadas 40 necessidades dos clientes a partir das respostas dos 55 questionários de campo aplicados e dos dados bibliográficos. A análise dessas necessidades permitiu identificar 27 requisitos de clientes, distribuídos ao longo de diversas fases do ciclo de vida de uma semeadora, para o projeto do produto.
\end{abstract}

PALAVRAS-CHAVE: semeadora de precisão, metodologia de projeto, ciclo de vida.

\section{IDENTIFICATION OF CLIENT'S REQUIREMENTS TO DESIGN A PRECISION METER FOR SMALL SEEDS}

ABSTRACT: The increasing cost of seeds for small grain crops makes it necessary to develop seeders with a more effective control over the stand of plants. This could be accomplished with the use of precision planters, but such equipment is only available for large seed crops. Because this is a new product, especial attention must be paid to the design process to be used, in order to consider all attributes involved in the fulfillment of such task, including those related to the machine functional performance as well as those expressing the product quality, market and production needs. Therefore, this study has the objective of presenting the client's requirements to design a precision meter for small seeds identified through the application of a field questionnaire to farmers, agricultural researches, salespersons, designers, and other information gathered in the bibliography. Forty clients' needs were brought about from the answers of the 55 questionnaires and bibliographical data. With the analysis of these needs, it was possible to identify 27 clients' requirements along the life cycle of a seeder, to be used in the product design.

KEYWORDS: precision planters, design methodology, product life cycle.

\footnotetext{
${ }^{1}$ Extraído da tese do primeiro autor.

${ }^{2}$ Eng $^{\mathrm{o}}$ Agrícola, Prof. Adjunto, DER/FAEM/UFPEL, Pelotas - RS, Fone: (0XX53) 275.7126, areis@ ufpel.tche.br

${ }^{3}$ Eng ${ }^{\underline{0}}$ Mecânico, Prof. Adjunto, Departamento de Engenharia Mecânica, CTC/UFSC, Florianópolis - SC.

Recebido pelo Conselho Editorial em: 5-9-2003

Aprovado pelo Conselho Editorial em: 21-3-2006
} 


\section{INTRODUÇÃO}

A elevação do custo das sementes, motivada pela seleção de cultivares com maior potencial produtivo e pela adoção de outras tecnologias, como sementes híbridas e a transgenia, torna necessário o desenvolvimento de semeadoras que tenham controle efetivo sobre a população de plantas, o que pode ser conseguido com a utilização de semeadoras de precisão. Essas máquinas possuem mecanismos dosadores que permitem a colocação de sementes espaçadas umas das outras, na linha de semeadura, com distâncias definidas, gerando, assim, potencial para a redução da quantidade de sementes utilizadas.

Uma análise do mercado de semeadoras feita por REIS \& FORCELLINI (2002) evidencia a ausência de semeadoras, tanto de fluxo contínuo como de precisão, capazes de trabalhar com baixas razões de distribuição de sementes miúdas (arroz, trigo, sorgo, cevada, aveia, centeio). Segundo os autores, no caso das semeadoras de precisão, isso se deve tanto à dificuldade de individualizar e transportar sementes de tamanho reduzido e de formas irregulares, quanto ao fato de essas culturas serem semeadas com pequenos espaçamentos entre linhas, requerendo mecanismos dosadores pequenos e estreitos, características ausentes nos mecanismos dosadores de precisão atualmente empregados. A maioria dos dosadores de precisão não permite o emprego de distâncias entre linhas inferiores a $0,35 \mathrm{~m}$ (REIS, 2003).

Por se tratar de um produto novo, sem similar no mercado, há que se prestar especial atenção ao processo de projeto que será utilizado, de forma que o produto incorpore todos os atributos indispensáveis ao cumprimento da tarefa a que se destina, incluindo-se, não somente aqueles de ordem funcional, mas também os de qualidade, os comerciais e os de fabricabilidade. Essas metas são mais facilmente obtidas pela adoção de um processo de projeto que tenha abordagem sistemática do problema. Segundo ULRICH \& EPPINGER (1995), uma metodologia de projeto estruturada (sistemática) oferece uma série de benefícios, como: tornar o processo de decisão explícito, atuar com lista de verificação das principais etapas e ser autodocumentável, criando uma cultura recuperável, a qual será útil em novos projetos. Essas características, aliadas à consideração formal do que necessita o mercado, aumentam significativamente a probabilidade de sucesso de um novo produto.

A metodologia de projeto empregada no desenvolvimento de um dosador de precisão para sementes miúdas é detalhada por REIS (2003). O autor ressalta que o processo de projeto é dividido em quatro fases: projeto informacional, projeto conceitual, projeto preliminar e projeto detalhado.

O presente trabalho insere-se na fase de projeto informacional, que consiste na análise detalhada do problema de projeto, buscando-se todas as informações necessárias ao pleno entendimento do problema. Nessa fase, evolui-se das necessidades dos clientes (declarações diretas, geralmente em linguagem subjetiva), passando pelos requisitos dos clientes (necessidades expressas em linguagem de engenharia), até as especificações do projeto, que compõem uma lista de objetivos a que o produto a ser projetado deve atender.

As informações técnicas necessárias são buscadas principalmente por meio de pesquisa bibliográfica, análise de sistemas similares e pelo emprego de questionários estruturados a partir do ciclo de vida do produto. No âmbito do processo de desenvolvimento de produtos, o ciclo de vida representa os diversos processos por que passa o produto entre a sua criação e o descarte, tais como: fabricação, montagem, instalação, operação, manutenção, uso, reutilização e retirada (ROOZENBURG \& EEKELS, 1995). Cada um desses processos, segundo esses autores, traz requisitos e necessidades para o novo produto. Dito de outra forma, a análise do ciclo de vida força a equipe de projeto a considerar todos os inter-relacionamentos do produto durante a sua existência. Associados a cada uma das fases do ciclo de vida há uma lista de clientes que irão, de alguma forma, relacionar-se com o produto e que se constituem nos interlocutores com quem se podem buscar informações técnicas 
específicas. REIS (2003) classifica os clientes em externos (usuários ou consumidores do produto), intermediários (pessoas responsáveis pela distribuição, marketing e vendas do produto) e internos (pessoal envolvido no projeto e na produção do produto).

Sendo assim, o presente trabalho tem o objetivo de apresentar os requisitos dos clientes identificados no processo de projeto de um dosador de precisão para sementes miúdas. Para tanto, também são apresentados os dados obtidos com a aplicação de um questionário de campo a agricultores, pesquisadores, vendedores, projetistas, assim como as demais informações técnicas que levaram à formulação de tais requisitos de projeto.

\section{MATERIAL E MÉTODOS}

A síntese das etapas e das tarefas da metodologia empregada para a identificação dos requisitos dos clientes para o projeto de um dosador de precisão para sementes miúdas é apresentada na Figura 1. Essas atividades são desenvolvidas na fase de projeto informacional do produto e constituem-se em prática comum em empresas de base tecnológica líderes em seus setores de atuação.

As principais fontes de informação utilizadas para a identificação dos requisitos dos clientes para o projeto do dosador de sementes foram dissertações e teses desenvolvidas na área de máquinas agrícolas, no Núcleo de Desenvolvimento Integrado de Produtos do Departamento de Engenharia Mecânica da UFSC. Nesses trabalhos, também se encontram informações provindas de diversos clientes ao longo do ciclo de vida de semeadoras, principalmente nas fases de produção, o que contribui para que sejam incluídos requisitos importantes quando se consideram esses produtos sob o ponto de vista das empresas de máquinas agrícolas.

O questionário empregado no levantamento das necessidades dos clientes ao longo do ciclo de vida de uma semeadora foi desenvolvido por uma equipe formada por Engenheiros Agrícolas, Engenheiros Mecânicos e um Engenheiro Agrônomo, a partir da metodologia proposta por REIS et al. (2003). Esses autores dividem o processo de projeto de um questionário em quatro etapas: (a) estabelecer as fases do ciclo de vida do produto; (b) definir os clientes do projeto; (c) elaborar questões para cada cliente do projeto, e (d) formatar o questionário. O uso dessa metodologia propiciou a identificação das informações necessárias ao projeto em cada fase do ciclo de vida de uma semeadora, como pode ser observado na Tabela 1. O desdobramento dessas informações e a observância cuidadosa das diversas orientações quanto ao formato resultaram num questionário com 22 questões (sendo que 19 delas são fechadas, de múltipla escolha, e três questões abertas), totalizando quatro páginas impressas.

Os questionários foram aplicados via correio eletrônico e em duas feiras agropecuárias, no período compreendido entre março e maio de 2001. Foram enviados 57 questionários a professores universitários, pesquisadores, estudantes de pós-graduação e engenheiros, todos eles relacionados profissionalmente com máquinas para a semeadura. Desses, retornaram 25 questionários devidamente respondidos, correspondendo a uma taxa de retorno de 43,9\%. Foram aplicados 16 questionários durante a II Expodireto/COTRIJAL na cidade de Não-Me-Toque - RS. Responderam fabricantes de semeadoras e de discos dosadores (pessoal de vendas, projeto e gerência), estando representados nessa amostra 14 fabricantes nacionais. Também foram aplicados 14 questionários durante a Expovárzea na cidade de Pelotas - RS. Responderam agricultores, extensionistas, pesquisadores e vendedores de semeadoras.

As necessidades dos clientes identificadas, tanto aquelas provindas da pesquisa bibliográfica quanto aquelas levantadas nas questões do questionário, não podem ser empregadas diretamente no desenvolvimento do produto. Conforme se sabe, as necessidades são expressas de forma subjetiva, de difícil aproveitamento no projeto, sendo necessário, portanto, traduzi-las para a linguagem de engenharia. 


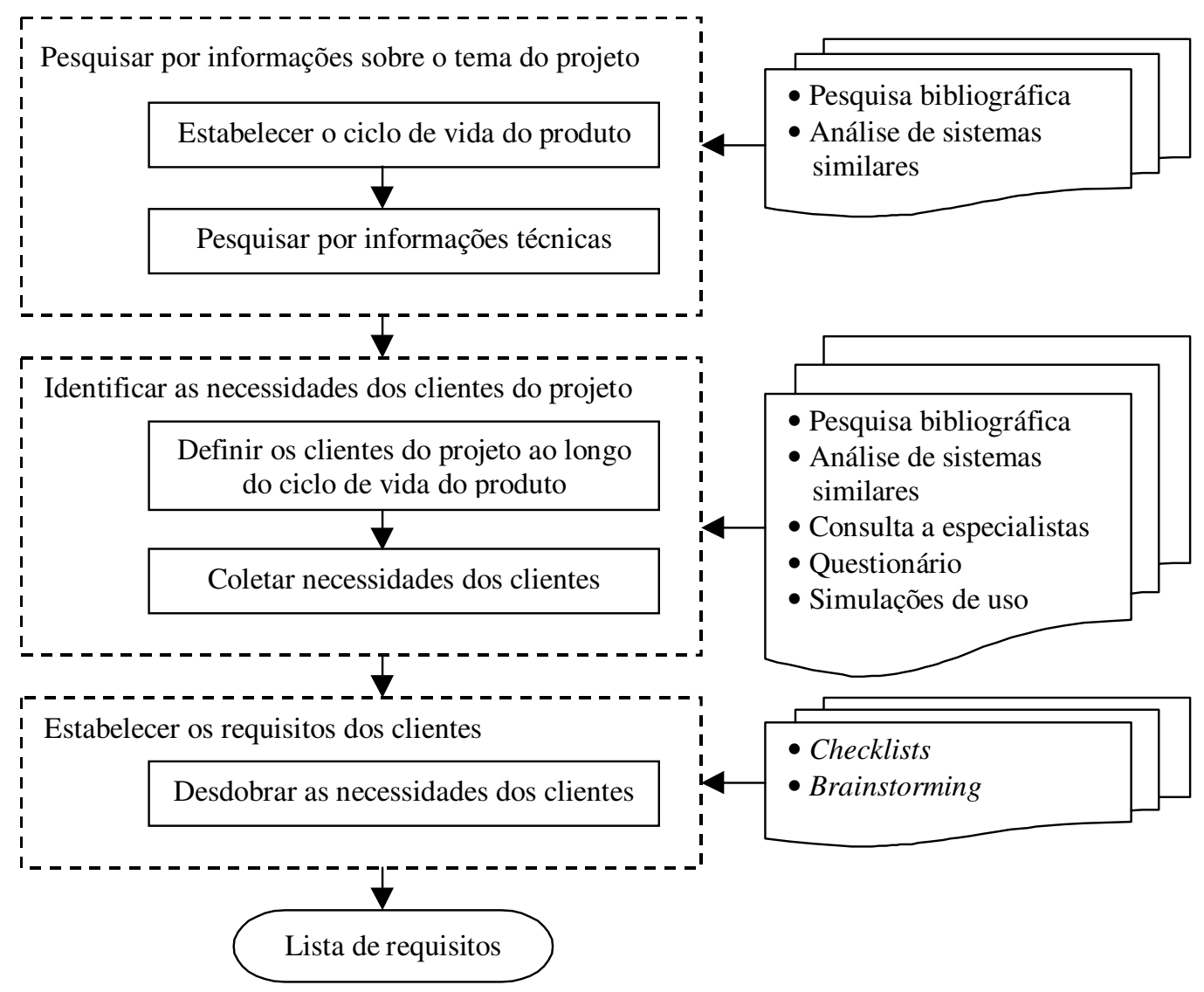

FIGURA 1. Seqüências das etapas e das tarefas da metodologia empregada para a obtenção dos requisitos dos clientes.

TABELA 1. Informações que devem ser coletadas em cada fase do ciclo de vida do produto.

\begin{tabular}{|c|c|}
\hline Fases do Ciclo de Vida & O que se deseja conhecer \\
\hline Projeto & $\begin{array}{l}\text { Máximo custo que o dosador e o depositor podem representar numa } \\
\text { semeadora. } \\
\text { O que é mais importante quando se considera a precisão funcional da } \\
\text { semeadora. } \\
\text { Aspectos desejáveis e indesejáveis num mecanismo dosador. }\end{array}$ \\
\hline Produção & $\begin{array}{l}\text { Características de fabricação desejáveis para a indústria. } \\
\text { Características de montagem desejáveis para a indústria. }\end{array}$ \\
\hline Comercialização & $\begin{array}{l}\text { Necessidade de adaptação à tecnologia de agricultura de precisão. } \\
\text { Vantagens do uso de dosadores de precisão para a dosagem de sementes } \\
\text { miúdas. }\end{array}$ \\
\hline Uso & $\begin{array}{l}\text { Principais problemas das semeadoras de fluxo contínuo e de precisão. } \\
\text { Motivação da compra. } \\
\text { Características operacionais desejáveis. } \\
\text { Aspectos de regulagem. } \\
\text { Aspectos de manutenção (mão-de-obra, freqüência, custo, acessos, } \\
\text { ferramental). }\end{array}$ \\
\hline
\end{tabular}

O desdobramento das necessidades dos clientes em requisitos dos clientes foi um trabalho feito em equipe. Em primeiro lugar, as necessidades levantadas foram distribuídas ao longo do ciclo de vida 
da semeadora a fim de identificar mais facilmente quais delas eram claramente redundantes. Posteriormente, cada uma das necessidades foi estudada e, se necessário, decomposta com o intuito de descobrir, em linguagem de engenharia, o que o cliente realmente queria.

Durante a conversão das necessidades dos clientes em requisitos, foram observadas as recomendações apresentadas por FONSECA (2000), quanto à forma dos requisitos dos clientes, a saber: a) frase curta composta pelos verbos ser, estar ou ter, seguidas de um ou mais substantivos, e b) frase curta composta por um verbo que não seja ser, estar ou ter mais um substantivo (nesse caso, possivelmente o requisito formará uma função do produto).

\section{RESULTADOS E DISCUSSÃO}

As perguntas, a estratificação dos respondentes e a síntese das respostas são apresentadas na Tabela 2.

TABELA 2. Perguntas e síntese das respostas obtidas com a pesquisa de campo.

\begin{tabular}{ll}
\hline \multicolumn{1}{c}{ Perguntas } & \multicolumn{1}{c}{ Síntese das respostas } \\
\hline 1- Qual das atividades abaixo melhor descreve & Agricultor (13); pesquisador (12); diretor, gerente ou supervisor \\
o seu envolvimento com semeadoras? & de empresa fabricante (9); professor (9); projetista de máquinas \\
& (4); vendedor de máquinas agrícolas (4); engenheiro - produção \\
& de máquinas agrícolas (2); extensionista (2); locador de \\
& máquinas (0). \\
\hline
\end{tabular}

2- As semeadoras com dosadores pneumáticos Sim (63\%); não (28\%); não sabe (9\%).

são, em sua opinião, mais precisas que aquelas

com dosadores de funcionamento mecânico?

3- As semeadoras com dosadores pneumáticos Sim (91\%); não sabe (9\%); não (0\%).

são, em sua opinião, mais caras que aquelas

com dosadores de funcionamento mecânico?

4- Você daria preferência para a utilização de Mecânicos (42\%); pneumáticos (36\%); indiferente (21\%).

semeadoras com dosadores?

5- Como você considera a capacidade da Muito importante (67\%); importante (21\%); pouco importante semeadora de semear grãos graúdos e miúdos $(6 \%)$; nenhuma importância (6\%); não sabe (0\%).

com pequenas alterações na configuração?

6- Quais são, em sua opinião, as principais características de um bom dosador de sementes?

Danifica pouco as sementes (17\%); elevada precisão na dosagem de sementes (17\%); fácil de regular (16\%); fácil manutenção (14\%); bom funcionamento mesmo em altas velocidades (10\%); dispensa a classificação prévia das sementes (7\%); baixo desgaste dos componentes (6\%); reduzido número de componentes (5\%); leveza (2\%); dispensa a adição de lubrificantes às sementes $(2 \%)$; tamanho reduzido $(1 \%)$; baixa potência de acionamento (1\%); outras (baixo custo de manutenção, precisão e uniformidade de distribuição de sementes, menor custo, facilidade de manutenção, dosar sementes de diferentes espécies na mesma semeadora) (2\%).

7- Em sua opinião, qual material deve ser utilizado na construção do dosador? Termoplástico (32\%); náilon (32\%); alumínio (16\%); ferro fundido (5\%); aço carbono (3\%); aço inoxidável (3\%); outros (náilon com ligas) (8\%).

8- Quais processos de produção devem ser preferencialmente empregados na fabricação do dosador? Injeção de plástico (42\%); usinagem (21\%); fundição (12\%); conformação a frio (2\%); forjamento $(2 \%)$; não sabe $(21 \%)$; outros (0\%).

9- Como você acha que deve ser a montagem das partes do dosador?

Manual sem o auxílio de ferramentas (55\%); manual com o auxílio de ferramentas (27\%); mecanizada (6\%); com emprego de ferramental específico (6\%); outros (0\%); não sabe (6\%). 
TABELA 2. Perguntas e síntese das respostas obtidas com a pesquisa de campo (continuação).

\begin{tabular}{ll}
\hline 10- Supondo a utilização de semeadoras de & Controle mais efetivo sobre a população de plantas (36\%); \\
precisão na semeadura de grãos miúdos (arroz, & redução no uso de sementes (30\%); possibilidade do uso de \\
trigo, sorgo, cevada, aveia, centeio), quais das & sementes de melhor qualidade (19\%); manutenção mais \\
alternativas a seguir melhor se aplicam em sua & complexa da semeadora (4\%); semeadoras mais caras (4\%); \\
opinião? & $\begin{array}{ll}\text { outros (uniformidade de distribuição de sementes, semear em } \\
\text { precisão e fluxo contínuo com a mesma máquina, uniformidade } \\
\text { mesmo em condições adversas) (6\%); não sabe (3\%). }\end{array}$
\end{tabular}

11- Como você classificaria a possibilidade de Muito importante (52\%); importante (33\%); pouco importante utilizar, com pequenas alterações na (12\%); nenhuma importância (3\%); não sabe (0\%).

semeadora, o mecanismo dosador já instalado,

para a agricultura de precisão (taxas de

semeadura variáveis)?

12- Quais são, em sua opinião, os principais problemas das semeadoras de fluxo contínuo empregadas na semeadura de grãos miúdos (como arroz, trigo, sorgo, cevada, aveia, centeio)?

Baixa precisão (26\%); dificuldade de regular os dosadores (19\%); dificuldade em se utilizarem baixas razões de distribuição de sementes (17\%); alta taxa de danificação das sementes (15\%); suscetibilidade a embuchamentos quando em condições de operação adversas (11\%); dificuldade em manter a profundidade de semeadura (9\%); alto preço (1\%); outros (sementes ficam em contato com o adubo o que prejudica as plântulas, falta de uniformidade entre linhas, não há problemas) ( $2 \%)$.

13- Quais são, em sua opinião, os principais problemas das semeadoras de precisão empregadas na semeadura de grãos graúdos (como milho, soja, feijão)?

Dificuldade de se utilizarem sementes não classificadas (24\%); alto preço (15\%); dificuldade de regular os dosadores (15\%); baixa precisão (12\%); alta taxa de danificação das sementes $(11 \%)$; dificuldade em manter a profundidade de semeadura (11\%); suscetibilidade a embuchamentos quando em condições de operação adversas (8\%); outros (excessiva demanda de potência, baixa precisão de fabricação, penetração no solo, emprego de pessoal qualificado, operação a mais de $5 \mathrm{~km} \mathrm{~h}^{-1}$ ) $(5 \%)$.

\begin{tabular}{ll}
\hline 14- Em sua opinião, para um mecanismo & Ser fácil de regular (45\%); ter manutenção simples (27\%); ser \\
dosador de sementes funcionar bem é preciso: & fácil de trocar partes (12\%); ser resistente a quebras (11\%); ser
\end{tabular} fácil de limpar (5\%).

15- Qual o tempo despendido diariamente com Entre 10 e 20 minutos (34\%); entre 20 e 30 minutos (28\%); mais a manutenção periódica da semeadora? de 30 minutos (15\%); menos de 10 minutos (9\%); não sabe $(13 \%)$.
16- Qual o tempo necessário para a substituição do disco de sementes de um dosador?

17- Quais são, em sua opinião, os aspectos mais críticos quando se considera a manutenção do dosador?

Menos de 5 minutos (56\%); entre 5 e 15 minutos (33\%); entre 15 e 25 minutos (6\%); mais de 25 minutos (0\%); não sabe (6\%).

Dificuldade de acesso ao dosador (29\%); manutenção muito freqüente $(17 \%)$; necessidade de uso de ferramentas (16\%); necessidade de mão-de-obra especializada (15\%); tempo despendido (13\%); custo elevado do serviço (4\%); outros (a própria manutenção, falta de conhecimento do operador, não há problemas) (5\%); não sabe (1\%).

18- No que se refere às regulagens do dosador, Deve haver bom número de regulagens a fim de tornar a qual situação você acha que seria mais apropriada? semeadura mais flexível (53\%); o mecanismo deve ser autoregulável (23\%); deve permitir a regulagem do número de sementes distribuídas e dos acessórios (19\%); deve permitir apenas a regulagem do número de sementes distribuídas (4\%); não sabe $(2 \%)$. 
TABELA 2. Perguntas e síntese das respostas obtidas com a pesquisa de campo (continuação).

\begin{tabular}{|c|c|}
\hline $\begin{array}{l}\text { 19- A precisão funcional de uma semeadora } \\
\text { caracteriza-se por sua habilidade em produzir } \\
\text { distribuição regular de plantas na linha de } \\
\text { semeadura. Sendo assim, em sua opinião, o } \\
\text { que mais influencia na precisão da semeadora? }\end{array}$ & $\begin{array}{l}\text { dosador (38\%); tubo condutor (24\%); sulcador }(15 \%) \text {; } \\
\text { controlador de profundidade ( } 12 \%) \text {; recobridor ( } 4 \%) \text {;oda } \\
\text { compactadora (4\%); outros (velocidade correta, altura do } \\
\text { dosador com relação ao solo, operação do sulcador e do } \\
\text { recobridor em velolcidades altas, classificaçãa adequada das } \\
\text { sementes, todos são importantes) }(5 \%) \text {. }\end{array}$ \\
\hline $\begin{array}{l}\text { 20- Qual o custo máximo admissível de um } \\
\text { sistema para a dosagem e deposição em } \\
\text { relação ao custo total de uma semeadora de } \\
\text { precisão com bom potencial de } \\
\text { comercialização? }\end{array}$ & $\begin{array}{l}\text { Resumo do custo máximo admissível: mínimo(3\%); média } \\
(14,8 \%) \text {; máximo }(30 \%) \text {. }\end{array}$ \\
\hline $\begin{array}{l}\text { 21- Quais fatores o levariam a adquirir ou } \\
\text { utilizar determinada semeadora? }\end{array}$ & $\begin{array}{l}\text { Agricultor: fator econômico (relação custo/benefício); baixa } \\
\text { manutenção; versatilidade, prática de usar; facilidade de } \\
\text { manutenção, durabilidade e baixo custo de aquisição; qualidade } \\
\text { de semeadura. }\end{array}$ \\
\hline $\begin{array}{l}\text { 22- Se achar necessário, faça outras } \\
\text { considerações quanto ao projeto, à regulagem, } \\
\text { à operação e à manutenção de semeadoras. }\end{array}$ & $\begin{array}{l}\text { Agricultor: linhas de semeadura mais próximas para o arroz, o } \\
\text { tubo de descarga não deve estrangular quando a máquina passa } \\
\text { sobre a taipa. }\end{array}$ \\
\hline
\end{tabular}

Na pergunta 20, somente foram consideradas as respostas dos clientes envolvidos nas fases internas do ciclo de vida da semeadora (projetistas, diretores, gerentes e vendedores), pois essas classes de respondentes têm conhecimento, mesmo que tácito, dos custos de produção das semeadoras, fornecendo, assim, dados mais confiáveis sobre o custo relativo admissível de um sistema de dosagem e deposição.

As respostas das perguntas 21 e 22 , que são abertas, ocuparam mais de três páginas impressas, razão pela qual se optou por apresentar neste artigo apenas as respostas dadas por respondentes agricultores. Todavia, as informações de todas as classes de respondentes foram integralmente utilizadas na síntese dos requisitos dos clientes.

A análise das respostas do questionário, tanto aquelas das questões de múltipla escolha quanto às das questões abertas, permitiu identificar algumas tendências dentro da amostra de respondentes obtida. A primeira delas é a preferência por semeadoras dotadas de dosadores com funcionamento puramente mecânico, mesmo admitindo que os dosadores pneumáticos de sementes apresentem maior precisão funcional (Figura 2). A explicação para essa contradição encontra-se no próprio questionário (questão três), no qual os respondentes dizem acreditar que as semeadoras pneumáticas são mais caras do que as dotadas de dosadores mecânicos de sementes. Essas idéias estão de acordo com outra constatação feita: a de que o mecanismo dosador, juntamente com o tubo condutor de sementes são os principais responsáveis pela precisão funcional da semeadora (Figura 3).

Também se identificou que não somente características funcionais desejáveis, como boa precisão funcional e baixa danificação de sementes, são atributos de um bom dosador. Os respondentes consideram igualmente importantes a facilidade de regular o dosador (preferencialmente sem o uso de ferramentas) e também a facilidade de manutenção desses mecanismos, evidenciando a necessidade de fácil acesso ao mecanismo dosador e suas partes (Figura 4) e o uso de materiais não-metálicos como os termoplásticos e o náilon. A identificação de atributos considerados importantes ligados ao uso e à manutenção dessas máquinas, além de confirmar a importância da consulta ao mercado na fase de projeto, também mostra a importância que os clientes do produto dispensam à eficiência do uso do equipamento e à redução do tempo ocioso desse no período da semeadura. 


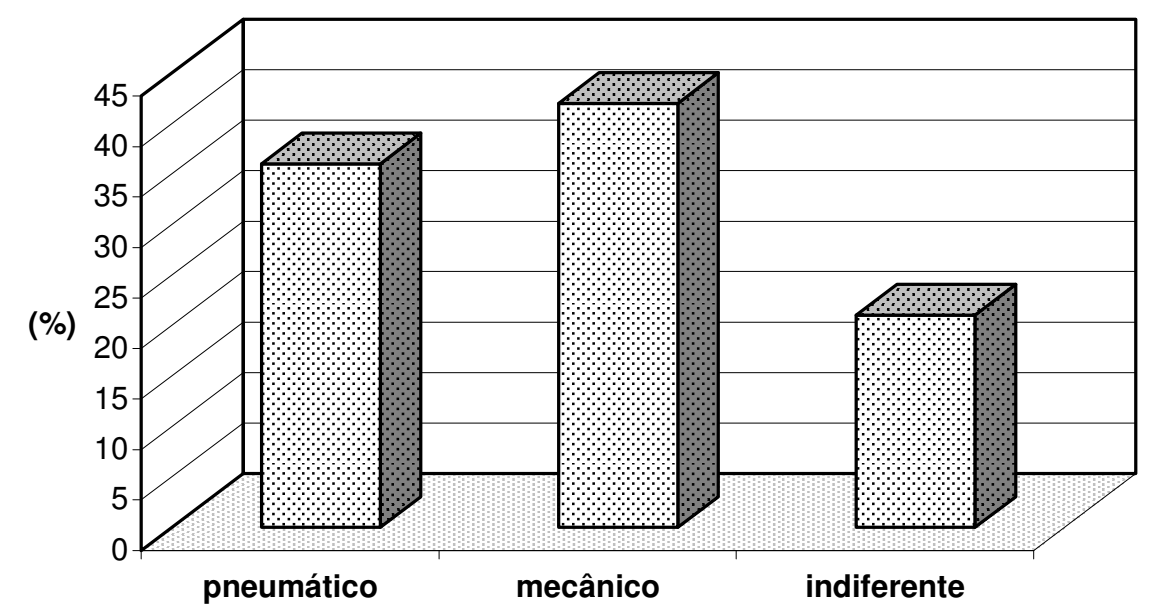

FIGURA 2. Preferência manifestada pelos respondentes quanto ao tipo de dosador.

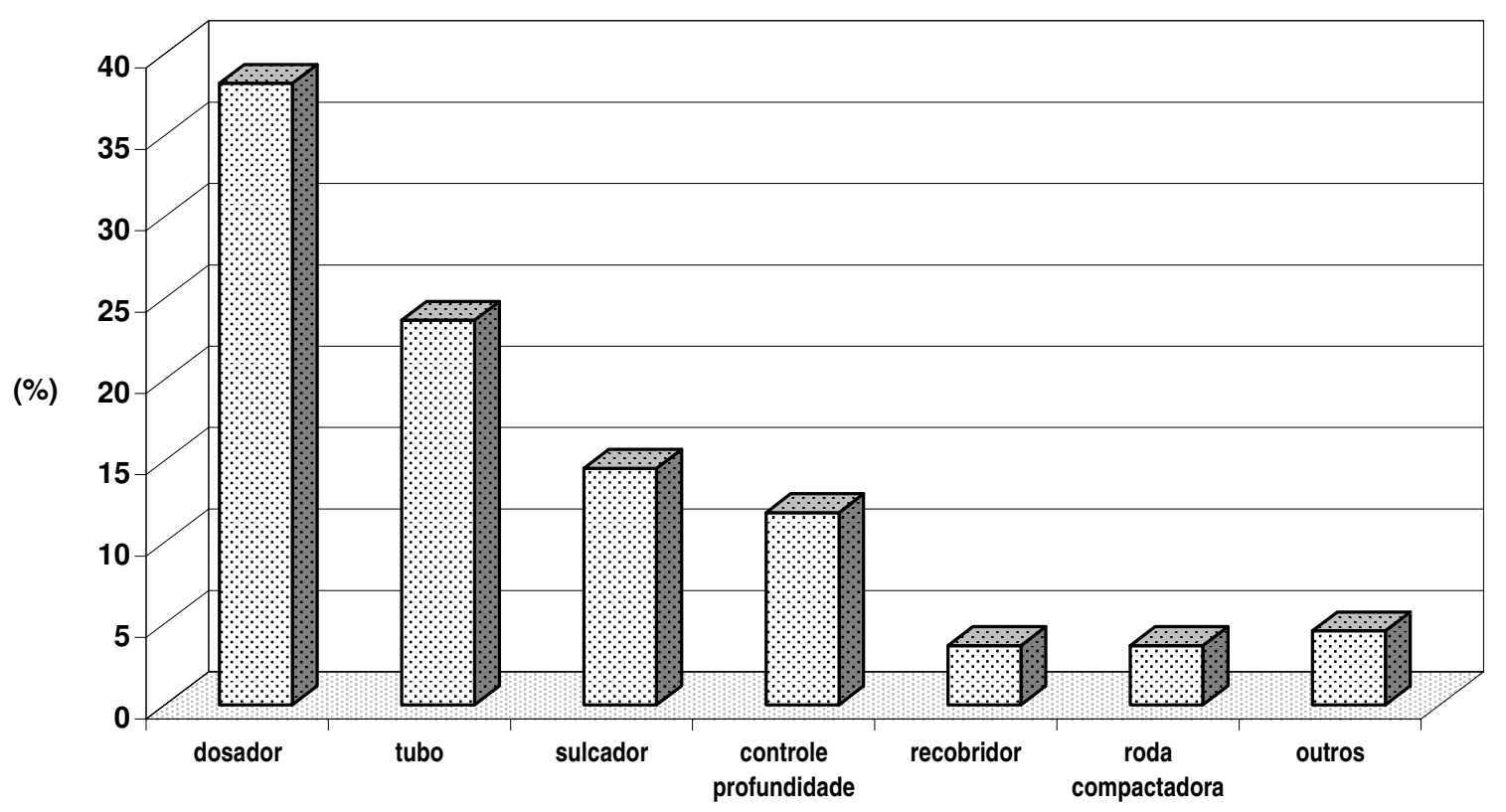

FIGURA 3. Componentes da semeadora que, segundo os respondentes, mais afetam a precisão.

Os principais problemas apontados nas semeadoras de fluxo contínuo atualmente empregadas foram a baixa precisão e a dificuldade de regular o dosador. Para as semeadoras de precisão, a dificuldade de trabalhar com sementes não classificadas foi apontada como o principal problema. Essa última constatação torna evidente que ainda há o predomínio das máquinas com dosadores de sementes mecânicos no mercado nacional, pois esses comprovadamente trabalham melhor com sementes classificadas por tamanho. 


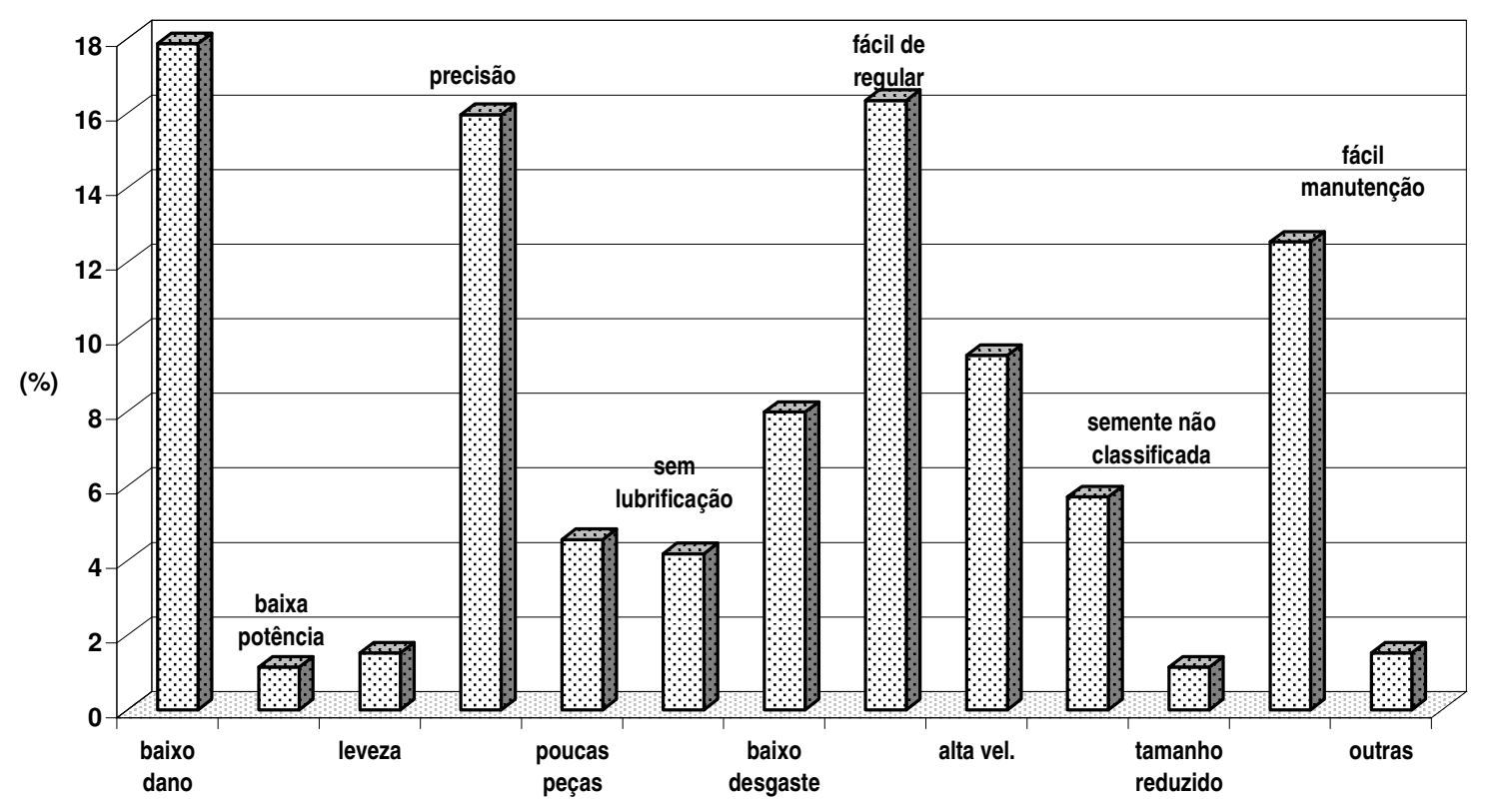

FIGURA 4. Características desejáveis em um bom dosador de sementes, segundo os respondentes.

A consideração das necessidades dos clientes coletadas na bibliografia, juntamente com aquelas identificadas por meio da análise das respostas dos questionários, permitiu a obtenção de 40 declarações de necessidades de clientes distribuídos ao longo do ciclo de vida do produto, conforme se pode observar na Tabela 3. Cabe salientar que, na união das informações de cada uma das fontes pesquisadas, as declarações redundantes foram excluídas. Esse processo foi facilitado pela categorização das necessidades, de acordo com as fases do ciclo de vida do produto, conforme foi proposto.

O estudo e o desdobramento das declarações de necessidades mostrados na Tabela 2, pela equipe de projeto, permitiram o estabelecimento dos requisitos dos clientes (necessidades expressas em linguagem de engenharia), conforme apresentado na Tabela 4. Os objetivos principais nessa fase de tratamento das informações são entender aquilo que os clientes do produto estão dizendo e gerar uma lista de requisitos bastante resumida, sem, no entanto, omitir informações relevantes para o projeto. Esse procedimento facilita as atividades subseqüentes dentro da fase de projeto informacional do produto.

Uma técnica utilizada na análise conjunta dos requisitos dos clientes em busca de redundâncias é a explicitação dos atributos, ou características intrínsecas, de cada um deles. Por exemplo, para o requisito do cliente ser fácil de regular, a equipe de projeto encontrou os seguintes atributos: entendimento simples da regulagem, acessibilidade das partes, facilidade de manuseio, regulagens com poucas interações, rapidez, efetividade. 
TABELA 3. Síntese das necessidades dos clientes de todas as fontes consultadas separadas por fases do ciclo de vida do produto.

\begin{tabular}{|c|c|}
\hline Fase do Ciclo de Vida & Declarações de Necessidades \\
\hline Projeto & $\begin{array}{l}\text { 1. Baixa rotação dos distribuidores } \\
\text { 2. Baixa influência da velocidade sobre o desempenho } \\
\text { 3. Funcionamento da semeadora deve ser independente da inclinação do terreno } \\
\text { 4. Necessidade de maior conhecimento de campo por parte dos projetistas } \\
\text { 5. Os projetistas devem pensar mais nas pessoas que vão operar a máquina } \\
\text { 6. Simplicidade }\end{array}$ \\
\hline Testes & 7. Todas as máquinas deveriam ser ensaiadas \\
\hline Produção & $\begin{array}{l}\text { 8. Precisão de fabricação } \\
\text { 9. Boa vedação } \\
\text { 10. Ausência de arestas cortantes e partes pontiagudas } \\
\text { 11. Utilizar o mínimo de operações de fabricação } \\
\text { 12. Simplificar o processo de fabricação } \\
\text { 13. Montagem manual do dosador sem o auxílio de ferramentas }\end{array}$ \\
\hline Comercialização & $\begin{array}{l}\text { 14. Carregar opções de funcionamento em doses variadas (agricultura de precisão) } \\
\text { 15. Possibilidade de semear três culturas simultaneamente, para adubação verde } \\
\text { 16. Baixa obsolescência }\end{array}$ \\
\hline $\begin{array}{l}\text { Uso de } \\
\text { Regulagens }\end{array}$ & $\begin{array}{l}\text { 17. Possibilidade de utilizar pequenos espaçamentos entre linhas } \\
\text { 18. O dosador deve trabalhar numa ampla faixa de densidade de semeadura } \\
\text { 19. Número máximo de regulagens possíveis } \\
\text { 20. Ser auto-regulável } \\
\text { 21. Regulagem manual } \\
\text { 22. Regulagem rápida } \\
\text { 23. Possuir sistemas de transmissão de movimentos simplificados e eficientes }\end{array}$ \\
\hline Operação & $\begin{array}{l}\text { 24. Operação independente do nível de conhecimento do operador } \\
\text { 25. Precisão na semeadura } \\
\text { 26. Baixa danificação de sementes } \\
\text { 27. Monitor eletrônico de semeadura } \\
\text { 28. Existência de estruturas de proteção } \\
\text { 29. Uso de sementes não classificadas } \\
\text { 30. Operar com sementes miúdas } \\
\text { 31. Operar com sementes graúdas }\end{array}$ \\
\hline Manutenção & $\begin{array}{l}\text { 32. Durabilidade } \\
\text { 33. Resistência } \\
\text { 34. Baixa manutenção } \\
\text { 35. Manutenção barata } \\
\text { 36. Manutenção fácil } \\
\text { 37. Facilidade de acesso aos pontos de manutenção } \\
\text { 38. Limpeza e retirada de sobras dos mecanismos } \\
\text { 39. Dispensar o máximo o uso de ferramentas } \\
\text { 40. Enferruja pouco }\end{array}$ \\
\hline
\end{tabular}

Dos 27 requisitos dos clientes a que se chegou com a conversão das necessidades obtidas na bibliografia e com a aplicação do questionário, apenas 13 estão ligados diretamente à operação da semeadora. Nota-se, portanto, que se noção de ciclo de vida do produto não tivesse sido utilizada, requisitos importantes, como, por exemplo, aqueles relacionados com a manutenção, provindos de necessidades claramente expressas pelos clientes, poderiam estar ausentes no projeto, pois o mais comum é que o usuário final do produto seja considerado como o único cliente de interesse. 
TABELA 4. Requisitos dos clientes separados por fases do ciclo de vida do produto.

\begin{tabular}{|c|c|}
\hline Fase do Ciclo de Vida & Requisitos dos Clientes \\
\hline Projeto & 1. Ter projeto simples \\
\hline Produção & $\begin{array}{l}\text { 2. Ter precisão de fabricação } \\
\text { 3. Ser de fabricação simples }\end{array}$ \\
\hline Comercialização & $\begin{array}{l}\text { 4. Permitir o funcionamento em doses variadas (agricultura de precisão) } \\
\text { 5. Ter baixa obsolescência } \\
\text { 6. Ter custo de produção baixo }\end{array}$ \\
\hline $\begin{array}{l}\text { Uso de } \\
\text { Regulagens }\end{array}$ & $\begin{array}{l}\text { 7. Permitir pequenos espaçamentos entre linhas } \\
\text { 8. Ter número de regulagens adequado } \\
\text { 9. Ser fácil de regular }\end{array}$ \\
\hline Operação & $\begin{array}{l}\text { 10. Ter montagem do dosador sem o auxílio de ferramentas } \\
\text { 11. Oferecer segurança ao operador } \\
\text { 12. Ter precisão na dosagem } \\
\text { 13. Ter precisão na deposição } \\
\text { 14. Ter pequena danificação de sementes } \\
\text { 15. Monitorizar a semeadura } \\
\text { 16. Ter desempenho funcional pouco influenciado pela velocidade } \\
\text { 17. Ter funcionamento independente da inclinação do terreno } \\
\text { 18. Ter funcionamento independente do nível de sementes } \\
\text { 19. Usar sementes não classificadas } \\
\text { 20. Semear sobre taipas } \\
\text { 21. Ter boa resistência mecânica } \\
\text { 22. Semear sementes miúdas }\end{array}$ \\
\hline Manutenção & $\begin{array}{l}\text { 23. Ser durável } \\
\text { 24. Ter manutenção reduzida } \\
\text { 25. Ter manutenção de baixo custo } \\
\text { 26. Ter manutenção fácil } \\
\text { 27.Possibilitar fechamento entre o dosador e o reservatório }\end{array}$ \\
\hline
\end{tabular}

\section{CONCLUSÕES}

A utilização da metodologia para o projeto e a formatação do questionário facilitou a obtenção das informações, o que ficou denotado por uma taxa de retorno dos questionários enviados por correio eletrônico de $43,9 \%$.

A análise das repostas dos questionários revelou, entre outras, as seguintes tendências na amostra de respondentes obtida: (a) preferência por semeadoras dotadas de dosadores com funcionamento puramente mecânico, mesmo admitindo que os dosadores pneumáticos de sementes apresentem maior precisão funcional; (b) o mecanismo dosador e o tubo condutor de sementes são os principais responsáveis pela precisão funcional da semeadora; (c) a facilidade de regular e de dar manutenção ao dosador (preferencialmente sem o uso de ferramentas) também são considerados atributos de um bom mecanismo; (d) os principais problemas das semeadoras de fluxo contínuo são a baixa precisão e a dificuldade de regular o dosador, enquanto, para as semeadoras de precisão, é a dificuldade de se trabalhar com sementes não classificadas.

A análise das 40 necessidades sintetizadas por meio da metodologia permitiu identificar 27 requisitos de clientes para o projeto de um dosador de precisão para sementes miúdas. 


\section{REFERÊNCIAS}

FONSECA, A.J.H. Sistematização do processo de obtenção das especificações de projeto de produtos industriais e sua implementação computacional. 2000. $180 \mathrm{f}$. Tese (Doutorado em Projetos de Sistemas Mecânicos) - CTC/EMC, Universidade Federal de Santa Catarina, Florianópolis, 2000.

REIS, A.V. dos. Desenvolvimento de concepções para a dosagem e deposição de precisão para sementes miúdas. 2003. 277 f. Tese (Doutorado em Projetos de Sistemas Mecânicos) - CTC/EMC, Universidade Federal de Santa Catarina, Florianópolis, 2003.

REIS, A.V.; FORCELLINI, F.A. Functional analysis in the evaluation of four concepts of planters. Ciência Rural, Santa Maria, v.32, n.6, p.969-75, 2002.

REIS, A.V.; MENEGATTI, F.A.; FORCELLINI, F.A. O uso do ciclo de vida do produto no projeto de questionários. In: CONGRESSO BRASILEIRO DE GESTÃO DE DESENVOLVIMENTO DE PRODUTO, 4., 2003, Gramado. Anais... Porto Alegre: UFRGS, 2003. 1 CD-ROM.

ROOZENBURG, N.F.M.; EEKELS, J. Product design: fundamentals and methods. Chichester: John Wiley \& Sons, 1995. 408 p.

ULRICH, K.T.; EPPINGER, S.D. Product design and development. New York: McGraw-Hill, 1995. $289 \mathrm{p}$. 